\title{
Cultural heritage and European identity in European Union law and policy
}

\section{Francesca Fiorentini, Kristin Hausler and Andrzej Jakubowski}

\section{Introduction}

According to the founding treaties of the European Union (EU), the EU coordinates, supports and supplements the policies and measures of its member states in cultural matters, without any power of legislative harmonization over them. ${ }^{1}$ This institutional structure is a consequence of the subsidiarity and proportionality principles underlying the nature of competences conferred to the EU, ${ }^{2}$ but above all reflects the member states' political will: they are very reluctant to lose legislative competence over cultural matters. Since the formation of modern nation states, culture has been established and maintained as a national competence, functional to the idea of nurturing a sense of national identity (e.g. Deutsch 1966).

This chapter builds on the results of the three-year HEURIGHT14 research project, ${ }^{3}$ which analysed the EU's legal and policy approaches to cultural herit-

See Art. 167 of the Treaty on the Functioning of the European Union (consolidated version) 2012 (TFEU).

Art. 5 Treaty on the European Union (consolidated version) 2012 (TEU).

The project 'The Right to Cultural Heritage - Its Protection and Enforcement through Cooperation in the European Union' (HEURIGHT14) was carried out by a consortium chaired by Dr Andrzej Jakubowski, Project Leader, University of Fine Arts, Poznan, and Polish Academy of Sciences, Warsaw, and managed by two other Principal Investigators: Kristin Hausler, British Institute for Comparative 
age in the context of the above-mentioned regulatory framework. In particular, the chapter underlines the links between the notions of 'cultural heritage' and the twin concepts of 'European cultural heritage' and 'European identity', with the latter having developed since the beginning of the European project with the specific political aim of supporting the integration process. It also attempts to assess the current meaning of these notions for the EU, and to point to possible future research paths in this field. The present chapter thus analyses references to cultural heritage in the EU's legal texts and documents and how it is acknowledged and protected in the constitutional and human rights framework of the EU. It also considers the potential limits of the 'participatory governance' model advocated by the Council of Europe (CoE) and the EU for cultural heritage. In that regard, the way the EU deals with the cultural heritage of minorities and immigrants is particularly relevant. Considering all of these issues allows the identification of a selected number of EU policy areas that still require further analysis, and from which recommendations for legal reform or improved organizational structures should be drawn.

\section{Cultural heritage, European identity and the European Union: building a link}

The designation of 2018 as the 'European Year of Cultural Heritage"4 was the culmination of years of efforts undertaken by the EU to integrate cultural heritage into its policies and actions. While the EU's (limited) competence in this field was only established by the Treaty of Maastricht in 1992, ${ }^{5}$ policy efforts to strengthen a feeling of belonging to the European polity and advance European integration had already led to a number of initiatives in the field of cultural heritage prior to Maastricht (Psychogiopoulou 2008, 7-24). In the 1970s and 1980s, the notion of a 'shared', 'common' or 'European cultural heritage' had already been introduced by the European Communities as a means to strengthen a sense of European identity through highlighting European values (e.g. De Witte 1987; García 1993), as well as through cultural heritage

and International Law, London, and Professor Francesca Fiorentini, Department IUSLIT, University of Trieste. It was a Heritage Plus project funded under the EU's Joint Programming Initiative on Cultural Heritage and Global Change (June 2015-May 2018).

4 See Decision (EU) 2017/864 of the European Parliament and of the Council of 17 May 2017 on a European Year of Cultural Heritage (2018) (Decision (EU) 2017/884).

5 See Arts 3, 128 and, subsequently, Arts 2(5), 6 and 167 TFEU. 
diplomacy initiatives (Scott 2019). Since then, the general concept of cultural heritage has vastly expanded, and has come to include not only architectural monuments and sites, museums, libraries and archives, but also 'traditions, transmitted knowledge, and expressions of human creativity' (CEU Press Release 52/17 2017). The concept of 'European cultural heritage', as adopted at the EU institutional level, is also now understood to include a 'shared source of remembrance, understanding, identity, dialogue, cohesion and creativity, [which] contributes to economic growth and social cohesion'. ${ }^{6}$ Furthermore, Europe's 'common cultural heritage' transcends the sum of member states' heritages, serving as an important, axiological foundation for the EU. Despite the fact that the conceptualization of cultural heritage has greatly developed over the past decades, a number of obstacles associated with its understanding still prevent it from becoming truly inclusive and thus unleashing its full potential in meeting the political desire to strengthen the European identity. These obstacles mainly pertain to the components of cultural heritage itself and their relations with one another, as well as to the legal conceptualization of cultural heritage within the EU legal system and the consequent impact it has on the European integration project.

\section{The conceptualization of cultural heritage in EU law and policy}

Identifying the precise components of cultural heritage is difficult as its legal notion - exactly like the notion of culture - is in constant flux (Blake 2000); it is also linked to national contexts and sometimes conflicting perspectives on history. As a result, its conceptualization is generally broadly encompassing but also unclear, for at least two reasons.

The first reason lies in the classification of a particular asset as 'cultural heritage', which implies a value-based decision, which may change from time to time. In particular, such a decision depends on the context and the interests attaching to it (e.g. Forrest 2010, 3ff). While some stakeholders - the general public, for example - may not have the authority to classify a particular object as cultural heritage, those who do have such authority may do so for different reasons, whether they are cultural experts (historians, archaeologists or curators) or government representatives. The second reason is that different

See Legislative Train Schedule: Culture and Education 2018 and Decision (EU) $2017 / 864$. 
manifestations of cultural heritage require different measures of protection, adding a layer of complexity to the wide range of stakeholders in cultural heritage matters. Carving out different legal regimes for different categories of cultural heritage is a challenge, given the multi-layered structure of governance in that field, where local, national and supranational levels intersect; there are also distinct lawmakers, such as governmental authorities, which may adopt both hard and soft law, or professional associations (museums, dealers, and so on) which may also adopt their own self-regulative instruments in the form of guidelines or standards (Fiorentini 2014).

In terms of providing legal protection to specific forms of cultural heritage, there are some fields that can be identified as still lacking adequate consideration at the legal and policy levels, such as intangible cultural heritage and cultural landscapes. Although EU policy documents and actions include 'intangible' aspects in the heritage discourse (e.g. the attempts by the European Parliament to create a narrative on 'musical and ethno-anthropological heritage'), they do so in an imprecise manner, which leads to a fragmented policy strategy for the safeguarding of intangible cultural heritage (Schreiber 2019). The EU appears to have so far strictly focused on tangible heritage as a vector for economic and social development; that is, contributing to the growth of cultural industries and creating jobs, but also contributing to social inclusion and cohesion and working as an element to strengthen identities. ${ }^{7}$

Similarly, the term 'cultural landscapes' remains unclear under EU law, despite the existence of international instruments specifically devoted to it, which have contributed to the identification of this notion. ${ }^{8}$ Under EU law, its conceptualization is limited, emphasizing the natural values of rural and/or cultural landscapes rather than cultural values and the ways in which people interact with and relate to those landscapes. This limitation is reflected in the recent amendment to Directive 2011/92/EU on the assessment of the effects of certain public and private projects on the environment (EIA Directive), which equates

One example of transnational cooperation financed by the EU and focused on intangible cultural heritage is the 2011-14 Cultural Capital Counts project which brings together ten areas from six central European countries with the joint aim of promoting the region's development on the basis of its traditions, knowledge and know-how and highlighting its intangible cultural heritage as part of this cooperation. The project has been implemented as part of the Central Europe Programme (Cultural Capital Counts 2018).

8 The European Landscape Convention 2000 promotes the protection, management and planning of European landscapes and organizes European cooperation in this field. Landscapes are here intended as a reflection of European identity and diversity (Preamble and Art. 5). See also World Heritage Centre (2018). 
landscape with a 'view'; in the Common Agricultural Policy, ${ }^{9}$ where the focus is on maintaining the rural scenic quality of agricultural landscapes (Fischler 2001); and within EU environmental law, where the emphasis is placed on nature and the protection of natural habitats (Kramer 1997). Cultural landscapes also entail intangible elements relating to the way in which they are being used, a dimension that should be better considered to ensure their effective protection (Strecker 2018, 113-28). The consequence of the fragmented conceptualization of cultural landscapes within the EU, dependent on other policy areas like agriculture or environment, is limited access to justice for breaches relating to cultural landscapes. This is due in particular to narrow standing requirements at the national level and the marginal status of cultural heritage within the EIA Directive.

In determining what cultural heritage means for the EU, emphasis has often been placed on certain specific manifestations or sites which have been formally recognized as part of 'European cultural heritage', such as those falling under the European Heritage Label (EHL) (Čeginskas 2018). For example, the EHL has been granted to the European District of Strasbourg, which 'bears witness to European integration, the defence of human rights, democracy and the rule of law', as well as to the Maastricht Treaty itself. The pressure to nominate some assets that differ from traditional monuments or sites clearly shows how heritage is instrumentally used by the EU for identity-building purposes (Kaiser 2014).

\section{The human dimension of cultural heritage in EU law and policy}

The notion of cultural heritage has evolved over time into a powerful legal concept linked to the identity of nations, communities and individual persons; however, this particular aspect has also not yet been fully taken into account under EU law and policy.

Although primary EU law does not formally define cultural heritage, its constitutional principles derive from international human rights instruments, which today also comprise reinforced cultural human rights. The general principles

E.g. Council Regulation (EC) No. 1257/1999 on support for rural development from the European Agricultural Guidance and Guarantee Fund (EAGGF) and amending and repealing certain Regulations 1999. 
of EU law thus include the rights guaranteed by the European Convention on Human Rights, embracing those that have been applied to enforce access to Europe's cultural heritage. The EU Treaties also refer to 'Europe's cultural heritage', 'bringing the common cultural heritage to the fore' and preserving 'cultural heritage of European significance', and address the 'commonalities' along with references to cultural diversity (e.g. 167 TFEU). Hence, it may be argued that within the EU legal space, everyone holds the human right to create, maintain and enjoy their heritage in a society based on freedom, democracy, equality and the rule of law, which also allows cultural diversity to flourish (e.g. Craufurd Smith 2004, 279-89). In addition, the EU and its member states are subject to international law and thus are bound to comply with their international human rights law obligations in the realm of cultural heritage (Hausler 2019). The humanization and constitutionalization of international cultural heritage law thus affect the cultural heritage provisions under EU law, particularly those referring to Europe's common cultural heritage. Given the international legal obligations pertaining to cultural heritage that bind member states, the legal conceptualization of cultural heritage should not only refer to what is relevant to Europe but also encompass its conceptualization at the international legal level.

Besides the primary sources of EU law and their relationship to international law, the judicial protection of cultural heritage at the European level is also relevant in shaping the actual level of protection and enjoyment of cultural heritage by individuals and public organizations. Indeed, the jurisprudence of the European Court of Human Rights (ECtHR) and the Court of Justice of the European Union (CJEU) have reached the field of cultural heritage and thus need to be considered. However, the former has not yet reached a holistic conceptualization of cultural heritage. For example, the ECtHR case law concerned with landscapes adopts a narrow understanding of the concept, one that is limited to their scenic or preservationist character, rather than including the relationship (or use/practice) between people and a place over time, as understood under cultural heritage law (Strecker 2019). As a result, only certain aspects of cultural landscapes can be the object of legal proceedings at the European level, with others being left out of the judicial system.

Access to the ECtHR is another issue. So far, when applicants have argued for landscape protection on the basis of human rights, their cases have almost always been dismissed based on a lack of standing and identifiable victims (e.g. Kyrtatos $v$ Greece). Therefore, the ECtHR has not yet adopted a conceptualization of cultural heritage in line with the current understanding at the global level; such a conceptualization might then trickle down to the CJEU. It is also worth noting that the CJEU does not yet refer to cultural heritage but rather 
still uses the term 'cultural objects' (formerly 'cultural goods'), even when referring to objects that have a symbolic, identity-formative value for a nation (Bieczyński 2019). This stresses not only the material aspects of cultural heritage but, especially, the (internal) market-oriented perspective of the CJEU (see e.g. Beyeler v Italy, para. 113). Of course, the limited conceptualization of cultural heritage by the CJEU also stems from the limited types of disputes it hears on the topic; that is, cases involving 'national treasures' and a national interest in preserving cultural heritage, from the angle of the freedom of circulation in the internal market (see Graziadei and Pasa 2019).

\section{The instrumentalization of cultural heritage}

The EU has sought to strengthen its role in cultural heritage governance, affirming that 'cooperation in heritage preservation, conservation and promotion, can only be achieved at the EU level'. Nevertheless, in accordance with the division of competences and the institutional structure set out in Article 167 TFEU, its role is limited to coordinating and supporting member states with their respective national competences (Legislative Train Schedule 2018).

However, the EU's policy actions in cultural heritage show that its institutions have sought to maximize the role of cultural heritage within the mentioned legislative limits, and this has occurred in parallel with the broadly encompassing understanding of cultural heritage gradually developed at the EU level. In particular, the EU has integrated the contribution of cultural heritage to social, (inter)cultural, political, educational, symbolic, economic and environmental values into a variety of policy areas beyond culture. However, the basis for its actions has not been consistent. The EU has sometimes based its actions on the 'transnational element' of the relevant activities concerned and the promotion of partnerships and networks; at other times, it has highlighted the European significance of heritage assets and events at the national or local level, as well as the duty of its institutions to promote cultural diversity and sustainable development. In most instances, even if cultural heritage is acknowledged and protected per se by EU law, with the limits stressed in this chapter, EU institutions have adopted an instrumental approach to cultural heritage (Council Conclusions on Cultural Heritage 2014, para. 9). This means that they have used cultural heritage as a medium: a vehicle to fulfil different aims, such as strengthening the European identity, fostering intercultural dialogue, supporting economic and social development, and promoting social inclusion. For instance, digitizing the collections of European museums, libraries and archives is not only a way to safeguard cultural heritage per se; by increasing 
access to it, it is also a means to democratize society and even increase participation in heritage governance (e.g. Council Conclusions on Participatory Governance 2014, para. 23). Digitization reinforces Europe's symbolic prestige and cultural status, both within the EU (as an element of integration) and towards the rest of the world. More specifically, it is an important means for integration with regard to the enlargement process. Inasmuch as its implementation has required the creation of jobs and an entire industry across Europe, digitization has also served as a motor for economic growth for the EU, as well as a means to exercise economic influence around the world, albeit not free of risks arising from the instrumentalization and commodification of heritage (Manikowska 2019).

\section{Cultural heritage governance: making the participatory model work}

The striving to strengthen European identity as a foundation for a successful European project is possibly at odds with the diversity of cultural practices implicit to heritage in a highly diverse continent. The EU promotes a 'participatory governance' model of cultural heritage as a tool to foster democracy, 'democratic participation, sustainability and social cohesion and to face the social, political and demographic challenges of today' (Council Conclusions on participatory governance 2014, para. 8). Assessing the level of protection of the cultural heritage of communities (and minorities in particular) allows us to identify possible obstacles to the implementation of this model. Within international human rights law, the cultural heritage of minorities is specifically protected as a means to exercise cultural rights as a group, as well as to enjoy their culture. ${ }^{10}$ However, the EU has not yet developed adequate principles pertaining to the cultural heritage of minorities, in particular those that are not officially recognized as such (Xanthaki 2019). Thus, minority communities usually only benefit from general measures protecting regional or local cultural heritage. Their heritage is even at risk of being appropriated by the majority and presented as national heritage. At the EU level, the concept of Europe's cultural heritage may exclude minorities' heritage, which may not be deemed as representative enough. The 'participatory governance' model should minimize the risks to minority cultural heritage. In order for the partic-

10 See the two fundamental instruments of the CoE: Framework Convention for the Protection of National Minorities 1995; Framework Convention on the Value of Cultural Heritage for Society 2005. 
ipatory model to be truly successful, policies should take cultural diversity into account and ensure that all minorities and communities are seen as stakeholders in the same way as experts or historians.

Stakeholders in cultural heritage also include migrants. With the migration crisis being one of the key challenges for the EU at present, offering sufficient protection to the cultural heritage of migrants may be a way to successfully address it. With regard to new migrants in particular, their cultural heritage is neither adequately recognized nor protected within the EU. At present, initiatives in the fields of cultural heritage and migration appear inconsistent (Chechi 2019), with programmes and actions aimed at building a cohesive and multicultural European society being limited by those actions adopted by the EU institutions and member states to control immigration. For example, those same EU institutions and EU states that have established the Creative Europe Programme (European Commission 2018) to celebrate the contribution that migrants have historically made to cultural diversity in Europe have responded to the recent mass movement of migrants and refugees by building legal and material barriers. It may also appear paradoxical that, while the $\mathrm{EU}$ is investing consistently in the safeguarding of cultural heritage in conflict areas, the cultural heritage of those fleeing those conflicts and arriving in Europe does not clearly fall under any specific protection measures.

Adopting and linking integration with management strategies would support the development of a successful participatory model in cultural heritage governance, one where all individuals may be effectively involved in the cultural life of the country they live in. In turn, this may facilitate a strengthened social inclusion and aid in avoiding marginalization and the rise of extremism. Awareness raising is also important in this regard, and could be aimed, for example, at educating the receiving state population about the migrants' cultural heritage.

\section{Conclusion}

At a time when the EU is facing pressing challenges - including armed conflicts and humanitarian crises in neighbouring regions, migration, threats to democracy and to the EU legal framework and integrity (including Brexit), terrorism, populism and economic difficulties - cultural heritage should continue to serve as an anchor for peace and a vector for well-being and development. Our research highlights that careful instrumentalization of cultural heritage, along the lines of the long-standing types of actions established by the EU insti- 
tutions as sketched above, will only become more relevant to counteracting disintegrative forces threating the European project. To ensure the strengthening of a constructive utilization of cultural heritage, coordination between European institutions should be reinforced and systematized. Our research has also pinpointed a number of key areas that need to be better considered. First, the participatory model of governance in the field of cultural heritage must be truly inclusive of all stakeholders, including vulnerable groups such as new migrants or members of minority groups; otherwise, existing imbalances may perpetuate exclusion rather than closing the gap. More generally, legal and policy instruments must specifically protect the cultural rights of those vulnerable groups, including their right to access and enjoy their cultural heritage. All legal and policy instruments must also adopt a holistic approach to cultural heritage; this means that they must not be limited to certain aspects of cultural heritage (e.g. monuments and sites) to the detriment of others. At the judicial level, the rule of law must be fully implemented with regard to cultural heritage. In particular, barriers to access to justice must be removed. For example, the European courts (ECtHR and CJEU) and domestic courts must fully grasp the current conceptualization of cultural heritage within the international human rights framework. Training on cultural heritage matters should be considered for lawmakers, policymakers and the judiciary, in order to ensure that the future instrumentalization of cultural heritage is constructive rather than destructive.

In addition, our research has concluded that the current challenges facing Europe should be addressed by legal instruments and operational technical tools which take into account the 'strong emotional link with Europe, a shared heritage and thus ... a vision of a shared future' (Pomian 2019, p. xxii). The existence of a common European cultural heritage should not be taken for granted. The recent crises (EU Open Data Portal 2017) may support the view that the EU has not yet established a unifying sense of European identity and shared European values. The research agenda envisaged in this book will be a useful means to reinforce an emotionally positive vision of a shared Europe and European identity, which is now vacillating. As demonstrated by our research, a form of heritage governance that is truly participatory could also contribute to global efforts in protecting and enhancing the cultural dimension of human existence. 


\section{References}

\section{Literature}

Bieczyński, M. (2019), "The "Right to Cultural Heritage" in the European Union: a tale of two Courts', in A. Jakubowski, K. Hausler and F. Fiorentini (eds), Cultural Heritage in the European Union - a Critical Inquiry into Law and Policy, Leiden, Netherlands and Boston, MA: Brill, 113-40.

Blake, J. (2000), 'On defining the cultural heritage', International and Comparative Law Quarterly, 49 (1), 61-85.

Čeginskas, V.L.A. (2018), 'The added European value of cultural heritage. The European heritage label', Santander Art and Culture Law Review, 4 (2), 29-50.

Chechi, A. (2019), 'Migration, cultural heritage, and cultural rights: a critical assessment of European Union law and policy', in A. Jakubowski, K. Hausler and F. Fiorentini (eds), Cultural Heritage in the European Union - a Critical Inquiry into Law and Policy, Leiden, Netherlands and Boston, MA: Brill, 294-323.

Craufurd Smith, R. (2004), 'Article 151 EC and European identity', in R. Craufurd Smith (ed.), Culture and European Union Law, Oxford: Oxford University Press, 277-97.

De Witte, B. (1987), 'Building Europe's image and identity', in A. Rijksbaron, W.H, Roobol and M. Weisglass (eds), Europe from a Cultural Perspective, The Hague, Netherlands: Nijgh \& Ditmar Universitair, 121-51.

Deutsch, K.W. (1966), Nationalism and Social Communication: An Inquiry into the Foundations of Nationality, 2nd edn, Cambridge, MA: Technology Press of the Massachusetts Institute of Technology.

Fiorentini, F. (2014), 'A legal pluralist approach to international trade in cultural objects', in J.A.R. Nafziger and R. Kirkwood Paterson (eds), Handbook on the Law of Cultural Heritage and International Trade, Cheltenham, UK and Northampton, MA, USA: Edward Elgar Publishing, 589-621.

Fischler, F. (2001), 'The European Union's rural development policy: protecting our heritage', Naturopa, 95, 20-21.

Forrest, C. (2010), International Law and the Protection of Cultural Heritage, London and New York: Routledge.

García, S. (ed.) (1993), European Identity and the Search for Legitimacy, London: Pinter.

Graziadei, M. and B. Pasa (2019), 'The Single European Market and cultural heritage: the protection of national treasures in Europe', in A. Jakubowski, K. Hausler and F. Fiorentini (eds), Cultural Heritage in the European Union - a Critical Inquiry into Law and Policy, Leiden, Netherlands and Boston, MA: Brill, 79-112.

Hausler, K. (2019), 'Cultural heritage within the European Union's external relations: more than a policy objective?', in A. Jakubowski, K. Hausler and F. Fiorentini (eds), Cultural Heritage in the European Union - a Critical Inquiry into Law and Policy, Leiden, Netherlands and Boston, MA: Brill, 365-94.

Kaiser, S. (2014), The European Heritage Label: A Critical Review of a New EU Policy (Thesis, Master of Arts in European Union Studies), University of Illinois, Urbana-Champaign, accessed 14 December 2018 at https://core.ac.uk/download/ pdf/29175015.pdf.

Kramer, L. (1997), Focus on European Environmental Law, 2nd edn, London: Sweet \& Maxwell. 
Manikowska, E. (2019), 'Digitization. Towards a European cultural heritage', in A. Jakubowski, K. Hausler and F. Fiorentini (eds), Cultural Heritage in the European Union - a Critical Inquiry into Law and Policy, Leiden, Netherlands and Boston, MA: Brill, 417-44.

Pomian, K. (2019), 'European heritage and the future of Europe', Foreword to A. Jakubowski, K. Hausler and F. Fiorentini (eds), Cultural Heritage in the European Union - a Critical Inquiry into Law and Policy, Leiden, Netherlands and Boston, MA: Brill, ix-xxii.

Psychogiopoulou, E. (2008), The Integration of Cultural Considerations in EU Law and Policies, Leiden, Netherlands and Boston, MA: Martinus Nijhoff Publishers.

Schreiber, H. (2019), 'Intangible cultural heritage, Europe, and the EU: dangerous liaisons?' in A. Jakubowski, K. Hausler and F. Fiorentini (eds), Cultural Heritage in the European Union - a Critical Inquiry into Law and Policy, Leiden, Netherlands and Boston, MA: Brill, 324-64.

Scott, C. (2019), 'Conceptions of a shared, common, or European heritage in the emerging heritage diplomacy of the European Union, 1973-92', in A. Jakubowski, K. Hausler and F. Fiorentini (eds), Cultural Heritage in the European Union - a Critical Inquiry into Law and Policy, Leiden, Netherlands and Boston, MA: Brill, 13-32.

Strecker, A. (2018), Landscape Protection in International Law, Oxford: Oxford University Press.

Strecker, A. (2019), 'The protection of cultural landscapes in the European Union', in A. Jakubowski, K. Hausler and F. Fiorentini (eds), Cultural Heritage in the European Union - a Critical Inquiry into Law and Policy, Leiden, Netherlands and Boston, MA: Brill, 395-416.

Xanthaki, A. (2019), 'The cultural heritage of minorities and indigenous peoples in the EU: weaknesses or opportunities?' in A. Jakubowski, K. Hausler and F. Fiorentini (eds), Cultural Heritage in the European Union - a Critical Inquiry into Law and Policy, Leiden, Netherlands and Boston, MA: Brill, 269-93.

\section{Legal and policy instruments}

Council conclusions on cultural heritage as a strategic resource for a sustainable Europe 2014

Council conclusions on participatory governance of cultural heritage 2014

Council Regulation (EC) No 1257/1999 on support for rural development from the European Agricultural Guidance and Guarantee Fund (EAGGF) and amending and repealing certain Regulations 1999

Decision (EU) 2017/864 of the European Parliament and of the Council on a European Year of Cultural Heritage (2018) 2017

Directive 2014/52/EU of the European Parliament and of the Council of amending Directive 2011/92/EU on the assessment of the effects of certain public and private projects on the environment 2014

European Landscape Convention 2000

Framework Convention for the Protection of National Minorities 1995

Framework Convention on the Value of Cultural Heritage for Society 2005

Treaty of Maastricht 1992

Treaty on the European Union (consolidated version) 2012

Treaty on the Functioning of the European Union (consolidated version) 2012 


\section{Case law}

Beyeler $v$ Italy, ECHR 2000-I 57

Kyrtatos $v$ Greece, ECHR 2003-VI 257

\section{Web sources}

CEU Press Release 52/17 (2017), 'European Year of Cultural Heritage in 2018: celebrating the diversity and richness of our European heritage', 9 February, accessed 12 December 2018 at https://europa.rs/european-year-of-cultural-heritage-in-2018 -celebrating-the-diversity-and-richness-of-our-european-heritage/?lang=en.

Cultural Capital Counts (2018), About the Project, accessed 10 December 2018 at http:// www.culturalcapitalcounts.eu/index.php/en.

EU Open Data Portal (2017), 'Special Eurobarometer 466: Cultural Heritage', 8 December (as updated), accessed 15 December 2018 at http://data.europa.eu/euodp/ en/data/dataset/S2150_88_1_466_ENG.

European Commission (2018), Creative Europe, accessed 10 December 2018 at https:// ec.europa.eu/programmes/creative-europe/node_en.

Legislative Train Schedule Culture and Education (2018), European Year of Cultural Heritage 2018, accessed 15 December 2018 at http://www.europarl.europa.eu/ legislative-train/theme-culture-and-education/file-european-year-of-cultural -heritage-2018.

World Heritage Centre (2018), 'Cultural Landscapes', accessed 12 December 2018 at https://whc.unesco.org/en/culturallandscape/. 
Francesca Fiorentini, Kristin Hausler, and Andrzej Jakubowski - 9781788974639 Downloaded from PubFactory at 04/26/2023 02:19:40PM 